\title{
A CASE OF GAS-POISONING WITH UNUSUAL OPHTHALMOLOGICAL COMPLICATIONS
}

\author{
BY \\ HAROLD GRIMSDALE
}

LONDON

THE case which is here reported is very unusual and therefore seems worth recording. It concerns a man, E.H., aged 32 years. He was married, with two healthy children; so far as could be ascertained his previous medical history had been good; his wife stated that so far as she knew 'he had always been strong and healthy, but that he had been slightly affected by gas about a month before the event which will be related. This gassing was not sufficient to incapacitate him even temporarily.

$\mathrm{He}$ is sewer man attached to a Gas Company's Works; he had held the same job for seven or eight years.

On February 15, 1932, being then in his normal health, he went to work and in the course of his employment at about 10 a.m. he went down into a sewer 14 feet below the surface; this sewer, which was within the area of the Gas Company's works, though connected with the main sewer, conducted the effluent from the sulphate of ammonia plant, and was, when he descended, being flushed with a stream of boiling water.

Soon after he had gone down-exactly how long is not knownhe called to the men above ground to send down a rope. They shouted down to him but had no answer; how long they waited I was not able to find out, but the delay courd not have been long, before one of his mates went down after him.

There was so much steam in the sewer that he could not see him; he came to the surface for a moment and then tried again, but again was unsuccessful; by this time the foreman had arrived and, wearing a gas mask, he went down. He found E. H. unconscious; apparently half-lying against the wall of the sewer; his right arm had fallen into the boiling water.

He was brought to the surface; artificial respiration was at once tried and oxygen inhalation given; an ambulance was sent for and by 11.15 a.m. he was admitted into St. James's Hospital. On admission he was in deep coma; he could not be roused; he had no control over the excreta, and made no effort to swallow. A lumbar puncture was done which proved negative. He had a severe scald of the right arm to a level above the elbow.

$\mathrm{He}$ remained in a state of coma for about four days. This was followed by a condition of cerebral irritation. He could be roused during this period by a loud voice, but he did not seem to be 
conscious of anything that was going on. He frequently shouted but his remarks were imprecatory without any corresponding cause. I saw him first on February 20 ; he seemed quite blind, paying no attention to any bright light flashed suddenly on the eyes, but the pupils reacted well to light and the fundi were normal. At first he made no movement of swallowing, but about the end of February a note was made that he swallowed well when food was placed in his mouth, but he made no effort to feed himself. It was stated also in a note made on February 24 that his sense of taste and smell seemed normal, but his mentality was so poor at this time, and for long after, that I should not like to place much dependence on this opinion. Improvement was very slow in all respects; in the early stages the bodily reflexes were absent or could not be elicited with the exception of the abdominal which were generally found, though on one occasion only the left upper reflex was present.

The pupil reflexes to light were always present.

The cerebral irritation was marked up to the end of March ; in the beginning of April he began to regain power over the excreta, and by the middle of that month he recognized by their voice, his wife and parents.

During this month slight wasting of the left arm was noted and wasting of the small muscles of the hand.

By June the burns of the right arm had healed, but with much contraction and deformity. His mentality was at this time that of a child about 4 years of age. His vision had improved to perception of light over a considerable field; owing to his mental state and the very poor vision, the field could not be taken accurately, but I thought it was normal to light or nearly so. He left the hospital at the request of his wife at the end of June. He was seen again in July and it was noted "V. p.l. Has perception of colours. Walks well; has some recollections of incidents before accident ; still cannot feed or dress himself without help."

My last note was in November, when I noted that his colour perception seemed relatively better than his light perception. The fundi remained normal and the discs of good colour.

Such is the history of this case ; what is the explanation? The Gas Company stated that it was not possible for carbon monoxide to be present in the sewer, but I think there can be little doubt that the primary coma was due to this gas; it will be remembered that he had been gassed before. according to his wife's statement, and there is no reason to doubt this. Does carbon monoxide poisoning account for all the sequelae?

Poisoning by illuminating gas is a comnaratively common event, but it is very rare to have any serious visual defect afterwards.

After a considerable search in the literature I have been able 
to find only a very few cases which are at all comparable to the present.

One case was recorded by Manzutto in La Clinica Oculistica, Vol. XI ; M. A., aged 70 years, was brought to him on April 7, 1911, with the following history. On the night of November 15-16, 1910 , she and her husband were overcome by an escape of gas, and were found unconscious at 11 a.m. on 16th. She did not recover consciousness for three days. On becoming conscious she at once found that she had lost all perception of light. Between that date and the time of Manzutto's examination she had regained a little sight, but only perception of hand movements close to the eyes. Pupil reaction was normal and the visual field seemed normal in extent though it could not be measured at all accurately as the vision was so imperfect. The fundi were normal. At the time of the examination, it is said that there was no disturbance of consciousness or intellect; all movements and speech were normal. Nothing is said about colour vision. It will be seen that though the visual symptoms were equally remarkable as those of E. H., the mental effects were much less.

Fejer, in the Amer. Jl. of Ophthal. for July, 1924, reported the case of a stoker, aged 52 years, who entered a tank containing coal gas, which he had thought to be empty. He was unconscious for a few minutes before being brought out. A few days after, his sight failed rapidly to hand movements ; but there was gradual and complete recovery. The pupils were normal throughout.

Lindemann, in Zeitschr. f. Augenheilk., Vol. LXI, 1927, reported a case of serious visual defect after a dynamite explosion. In this case there was severe papilloedema, so there is only slight resemblance to the case of $\mathrm{E}$. $\mathrm{H}$.

In 1933 Wechsler reported in the Arch. of Ophthal. the case of a boy, H. B., aged 13 years, who was overcome by smoke from a fire which broke out in his home; some of the family died. He had been up to the time of the fire (August, 1929) rather mentally advanced for his age. He was unconscious for two hours; when revived he was blind and could neither hear nor speak. The pupils were equal and active and there were noted to be retinal haemorrhages. In March, 1930, he began to see a little; he could recognize large objects, and could tell colours accurately and at once. His sense of smell was normal. Mentally he had failed and his mental age was estimated to be $\tau$ years and 8 months.

It is at least very rare for gas poisoning to be followed by so many serious symptoms, though illuminating gas is one of the commoner lethal poisons. Death occurs through the action of the carbon monoxide, and it is generally assumed that this gas is the cause also of the destruction of nerve cells which has been shown to follow gas poisoning in severe cases. But I think we are 
not entitled to assume this. Illuminating gas and other gases which give rise to carbon monoxide coma are not pure carbon monoxide, but contain many other carbon compounds, and there is some evidence that these are more toxic to nerve tissue than carbon monoxide.

In $1922 \mathrm{H}$. W. Haggard in the Amer. Jl. of Physiol., Vol. LX, published the account of a very interesting series of experiments bearing on this point.

He had shown that it was possible to take the neuroblasts from an early chick embryo and to grow them in suitable media, in hanging drop culture. He found that grown over air, 86 per cent. of the cultures lived; he then replaced the air by a mixture of gases in which carbon monoxide took the place of the atmospheric nitrogen. In this case 90 per cent. of the cultures developed, showing that carbon monoxide was not unfavourable to the developing neuroblasts.

When he admitted a very small amount of illuminating gas to the chamber (one part in a thousand) all the cultures died at once, showing that there was some very active poison in the new mixture; in so far as I am aware, there has been no further attempt to discover which of the various elements of illuminating gas are specially poisonous to nerve cells, but these experiments are sufficient to make it improbable that all the toxic effects are due to carbon monoxide.

I am indebted to Dr. David Kerr of St. James's Hospital for the notes of the medical condition of $\mathrm{E}$. $\mathrm{H}$. throughout his stay in the hospital.

\title{
A CLASSIFICATION OF CASES OF CONCOMITANT STRABISMUS BASED ON THE AETIOLOGICAL FACTOR
}

\author{
BY
}

\author{
M. A. PUGH
}

LONDON

IN the evolution of the treatment of squinting there have arisen from time to time, various theories as to its cause. Each new theory claimed to replace ideas previously held.

Thus, in 1827, Anthony White suggested that as a squint could be cured by a myotomy the original defect was entirely muscular in origin. In 1864 Donders pointed out the connection between hypermetropia and convergent squint, and between myopia and 